\title{
Corrosion Protection of Carbon Steel by Poly (aniline-co-o-toluidine) and Poly (pyrrole-co-o-toluidine) Copolymer Coatings
}

\author{
Nelofar Tanveer* and M. Mobin \\ Department of Applied Chemistry, Faculty of Engineering and Technology, Aligarh Muslim \\ University, Aligarh 202002, India. Tel. +91-9359544615, Fax. +91-0571-2701895 \\ *Corresponding Author: nelofar_tanveer@rediffmail.com
}

\begin{abstract}
The soluble copolymers, poly (aniline-co-o-toluidine) and poly (pyrrole-co-o-toluidine) were synthesized by chemical oxidative copolymerization using ammonium persulphate as an oxidant in hydrochloride aqueous medium and characterized by FTIR spectroscopy. The polymers were dissolved in $\mathrm{N}$-methyl-2-pyrrolidone and casted by solution evaporation on to the metallic substrate. The corrosion performance of the poly (aniline-co-o-toluidine) and poly (pyrrole-co-o-toluidine) coatings on carbon steel was studied by conducting immersion tests and electrochemical tests which include free corrosion potential measurements and potentiodynamic polarization measurements. The tests were conducted in $0.1 \mathrm{M} \mathrm{HCl}$ and 5\% $\mathrm{NaCl}$ solution. The performance of coating in open atmosphere was also evaluated by conducting atmospheric exposure test. The surface morphology of the copolymer coatings were studied by scanning electron microscopy (SEM). The anticorrosive properties of copolymer coatings were also compared with polyaniline and poly (o-toluidine) coatings. In general the performance of poly (aniline-co-o toluidine) copolymer was found better than poly (pyrrole-co-o-toluidine) and homopolymer.
\end{abstract}

Keywords: Corrosion protective coatings, Aniline, Pyrrole, Oxidative copolymerization.

\section{INTRODUCTION}

A number of methods for the protection of metals against corrosion are known, but looking for new method of corrosion control continues to be subject of intensive research. Interest has recently been focused on the possible use of conducting polymers as either film-forming corrosion inhibitors or in protective coatings [1-4]. The conducting polymers with their unique combination of physical and chemical properties, possibility of both chemical and electrochemical synthesis, distinct electronic properties, diversity, processing advantages of 
conventional polymers and potentially low cost have drawn the attention of scientists and engineers during the last few years and are greatly researched materials for corrosion protection $[5,6]$. The conducting polymers coating works as an oxidant to the substrate metal and makes a stable oxide film i.e. passivation film on the metals. Among large number of conducting polymers polypyrrole (PPy) [7-9] and polyaniline (PANi) [10-13] are the most promising conducting polymers used for corrosion protection. One of the challenges in developing conducting polymer coatings in general, has been to overcome the difficulty in processing these materials. The general lack of solubility and fusiblity of these materials make the formation of coating on active metals difficult. The electrodeposition of conducting polymers is a popular option but the process is difficult and involves a complicated mechanism.

The copolymerization has been utilized to enhance the stability and adherence of polymeric films [14]. Wei and coworkers [15,16] reported that aniline could be copolymerized with otoluidine to give rise to a copolymer film, the conductivity of which can be controlled over a wide range. Bereket et al. [17] reported the electrochemical synthesis of poly (aniline-co-2anisidine) films on stainless steel and examined the corrosion properties or these copolymer coatings in $0.5 \mathrm{M} \mathrm{HCl}$ solution by potentiodynamic technique, open circuit potential measurements and electrochemical impedance spectroscopy. In a recent study, a ter-polymer film of pyrrole, o-anisidine and o-toluidine was electrochemically synthesized on low carbon steel [18]. The synthesized ter-polymer film was found to be completely different in aspect of morphology, stability and other structural properties when compared to single polypyrrole film. Further, it has been observed that copolymers have better soluibility than their homopolymers in various organic solvents. This simplifies polymer processiblity and is advantageous for producing polymers and copolymer in bulk [19]. Polytoluidine is reported to exhibit better solubility [20] and processibility [21] than polyaniline and polypyrrole [22]. Attempts have been made to solubilise pyrrole polymer by introducing one or two long aliphatic substituents groups on every pyrrole ring and copolymerizing pyrrole with other monomers and same in case of aniline.

In the present investigation soluble copolymers of pyrrole and aniline with o-toluidine were prepared by oxidative copolymerization. The copolymerization of aniline and pyrrole with toluidine is expected to greatly modify the solubility of polypyrrole and polyaniline. The resultant copolymers were deposited on mild steel by solution evaporation. The anticorrosive properties of both copolymers were investigated in major corrosive environments by subjecting it to different corrosion tests. The anticorrosive property of copolymers was also compared with the individual homopolymer.

\section{EXPERIMENTAL}

\subsection{Preparation of Specimen}

The chemical composition (by wt \%) of the mild steel used in this study was: $0.20 \% \mathrm{C}$, $0.043 \% \mathrm{~S}, 0.028 \% \mathrm{P}, 0.003 \% \mathrm{Si}, 0.08 \% \mathrm{Ni}, 0.113 \% \mathrm{Mo}, 0.16 \% \mathrm{Mn}, 0.052 \% \mathrm{Cu}$ and 
balanced iron. The mild steel substrates (size $\sim 40 \times 15$ and $1.3 \mathrm{~mm}$ thick) were polished with a series of emery papers, followed by rinsing in acetone and double distilled water and dried in air. Prior to any experiment, the substrates were treated as described and freshly used with no further storage.

\subsection{Synthesis and Characterization of Poly (aniline-co-o-toluidine) and Poly (pyrrole-co- o-toluidine) Copolymer}

Poly (aniline-co-o-toluidine) [14] and poly (pyrrole-co-o-toluidine) [23] copolymers were synthesized by chemical oxidative copolymerization following a previously described method. Polymerization was carried out by using ammonium persulphate as an oxidant in hydrochloride aqueous medium. Polyaniline and poly (o-toluidine) were also polymerized by following the identical synthetic route. The copolymers were characterized using FTIR technique.

\subsection{Solubility of Poly (aniline-co-o-toluidine) and Poly (pyrrole-co-o-toluidine) Copolymer}

To evaluate the solubility of the copolymers, a polymer powder sample of $5 \mathrm{mg}$ was added to the solvent of $0.5 \mathrm{~mL}$ and dispersed thoroughly. After the mixture was swayed continuously for $24 \mathrm{~h}$ at room temperature, the solubility of the polymers was characterized.

\subsection{Preparation of Coatings on Mild Steel}

The coatings of poly (aniline-co-o-toluidine), poly (pyrrole-co-o-toluidine), polyaniline and poly (o-toluidine) were separately deposited on mild steel samples using N-methyl-2Pyrrolidone (NMP) as the solvent. The solutions of poly (aniline-co-o-toluidine) copolymer and poly (o-toluidine) (50\% weight) were prepared separately in NMP. In case of poly (pyrrole-co-o-toluidine) and polyaniline, a saturated solution of polymers were also prepared separately in NMP and spread on the mild steel surface with the help of a dropper; this was followed by evaporation of the solvent at a temperature $85-90{ }^{\circ} \mathrm{C}$ [24]. To get a thick and uniform coating of the polymers, controlled amount of solution was placed on the specimen. The amount of the polymer coatings on the steel surface was maintained to $5.40 \mathrm{mg} / \mathrm{cm}^{2}$ with a variation of $\pm 5 \%$. A strongly adherent dark coloured coating of copolymer on carbon steel was successfully obtained. The coating of poly (aniline-co-o-toluidine) copolymer was found to be more dense and uniform than poly (pyrrole-co-o-toluidine) and homopolymer coatings. A morphological analysis was conducted using scanning electron microscopy (SEM) with a (Model: FEI, Quanta 200).

\subsection{Corrosion Tests}

In order to evaluate the corrosion protection performance of the polymer coatings in different corrosive environments uncoated, coated and coated scribed mild steel specimens were 
subjected to immersion test, open circuit potential measurements and potentiodynamic polarization measurements in $0.1 \mathrm{M} \mathrm{HCl}$ and $5 \% \mathrm{NaCl}$ solution. The coated samples were also subjected to open atmospheric exposure test. The tests were done at room temperature under static condition.

\subsubsection{Immersion test}

After taking the initial weight and dimension, the specimens were hanged in test solution with the help of nylon thread. The tests were carried out under static condition at room temperature for a period extending 30 days. The corrosion rate was calculated from determination of total iron ions $\left(\mathrm{Fe}^{2+}, \mathrm{Fe}^{3+}\right)$ entered into the test solution in the course of corrosion during immersion. The analysis was performed spectrophotometrically [24, 25] using a single beam spectrophotometer [Model: Elico-SL-169 UV- Visible Spectrophotometer]. The corrosion rate was calculated using the following relationship:

$$
\text { Corrosion rate }=\frac{m}{s \times t}\left[\mathrm{gm}^{-2} \mathrm{~h}^{-1}\right]
$$

Where, ' $m$ ' is the mass of corroded metal (calculated from the total iron content determined in the test solution); ' $\mathrm{s}$ ' is the area of the test metal in $\mathrm{m}^{2}$; and ' $\mathrm{t}$ ' is the exposure time in hrs. The protection efficiency (\%PE) of the coated specimen was evaluated using the following equation:

$$
(\% P E)=\frac{C R u-C R c}{C R u} \times 100
$$

where, $C R u$ is the corrosion rate of mild steel in absence of coating and $C R c$ is corrosion rate of mild steel in presence of coating.

\subsubsection{Free corrosion potential measurements}

The free corrosion potential measurements of uncoated, coated and coated scribed specimens were carried out in $0.1 \mathrm{M} \mathrm{HCl}$ and $5 \% \mathrm{NaCl}$ solution. The change in voltage against saturated calomel electrode (SCE) used as reference electrode was plotted vs time. The potential measurement in a particular medium was continued till a steady state was obtained or it went down to the potential of bare steel.

\subsubsection{Potentiodynamic polarization measurements}

The potentiodynamic polarization measurements were carried out on an EG\&G potentiostat/galvanostat model $263 \mathrm{~A}$. The experiments were carried out using a corrosion cell from EG\&G model $\mathrm{K} 0047$ with $\mathrm{Ag} / \mathrm{AgCl}$ electrodes (saturated $\mathrm{KCl}$ ) as reference and $\mathrm{Pt}$ wire as counter electrode. The potentiodynamic polarization measurements were performed 
by sweeping the potential between -0.25 and $0.25 \mathrm{~V}$ from open circuit potential at a scan rate of $0.001 \mathrm{~V} / \mathrm{s}$. The specimen was allowed to stabilize in the electrolyte for $30 \mathrm{~min}$ prior to the experiment. All the measurements were repeated at least four times to ensure good reproducibility of the results.

\subsubsection{Atmospheric test}

The poly (aniline-co-o-toluidine), poly (pyrrole-co-o-toluidine), polyaniline and poly (otoluidine) coated steel samples along with uncoated steel sample were weighed and subsequently fixed on a panel which stood on a heavy metallic base and placed at the roof of the department. The exposure time was 30 days. The samples were taken off from the panel after the completion of the exposure test and physically examined. The samples were immersed in distilled water and were immediately subjected to potentiodynamic polarization measurements.

\section{RESULTS AND DISCUSSION}

\subsection{FTIR Spectra of the Poly (aniline-co-o-toluidine) and Poly (pyrrole-co-o-toluidine)}

The FTIR spectrum of poly (aniline-co-o-toluidine) and poly (pyrrole-co-o-toluidine) is shown in [Fig. 1 (a) and (b)]. The spectrum of the poly (aniline-co-o-toluidine) [14] and poly (pyrrole-co-o-toluidine) [23] copolymer is consistent with the reported spectrum of copolymer. The poly (aniline-co-o-toluidine) show the broad band centered at $3377 \mathrm{~cm}^{-1}$, a result of the characteristics free $\mathrm{N}-\mathrm{H}$ stretching vibration, suggests the presence of secondary amino group (-NH-). The small shoulder band at $3293 \mathrm{~cm}^{-1}$ corresponds to the hydrogenbonded $\mathrm{N}-\mathrm{H}$ vibration. The peak at about $3029 \mathrm{~cm}^{-1}$ might be because of $\mathrm{C}-\mathrm{H}$ stretching on the benzene ring. The peak at $2917 \mathrm{~cm}^{-1}$ can be attributed to the $\mathrm{C}-\mathrm{H}$ stretching vibration in methyl groups and gets a little bit stronger with OT unit. The IR absorption at 1489-1597 $\mathrm{cm}^{-1}$ is associated with the aromatic ring stretching. The peak at exactly $1597 \mathrm{~cm}^{-1}$ can be assigned to the quinoid ring and the one at $1489 \mathrm{~cm}^{-1}$ to the benzenoid ring. The weak peak at $1379 \mathrm{~cm}^{-1}$ can be attributed to the $\mathrm{C}-\mathrm{N}$ stretching vibration in the quinoid imine units. A strong peak at $1304 \mathrm{~cm}^{-1}$ is because of the $\mathrm{C}-\mathrm{N}$ stretching vibration in the alternative unit of quinoid-benzenoid-quinoid. A similar sequential structure is observed in the spectra of polyaniline. A weak peak at $1236 \mathrm{~cm}^{-1}$ can be ascribed to the $\mathrm{C}-\mathrm{N}$ stretching in the benzenoid-benzenoid-benzenoid triad sequence. The peaks at $1113 \mathrm{~cm}^{-1}$ and $879 \mathrm{~cm}^{-1}$, respectively, should be the result of the $\mathrm{C}-\mathrm{H}$ in plane and $\mathrm{C}-\mathrm{H}$ out-of-plane bending vibration of the 1,2,4-trisubstituted benzene ring on OT unit. In [fig 1 (b)] broad and weak band centered at $3350-3228 \mathrm{~cm}^{-1}$, is attributed to the characteristics $-\mathrm{NH}-$ stretching vibration, suggest the presence of $-\mathrm{NH}$ - groups in o-toluidine and pyrrole units. Four peaks at $3022,2960,2915$ and $2856 \mathrm{~cm}^{-1}$ should be attributed to aromatic and aliphatic $\mathrm{C}-\mathrm{H}$ stretching vibrations, respectively. The characteristics of IR absorption spectrum of poly (pyrrole-co-o-toluidine) copolymer above $2000 \mathrm{~cm}^{-1}$ are strongly influenced by the pyrrole 
units. The bands at about 1598, 1163 and $949 \mathrm{~cm}^{-1}$ is proposed to be characteristics of polypyrrole.

\subsection{Solubility of Poly (aniline-co-o-toluidine) and Poly (pyrrole-co-o-toluidine) Copolymer}

These copolymers are basically soluble in NMP, DMSO, chloroform, and tetrahydrofuran, and partially soluble in benzene. The high solubility of the copolymer is attributed to the presence of large number of methyl substituent on the aniline and pyrrole ring, which increased the distance between the macromolecules chains and then significantly reduced the interaction between the copolymer chains.

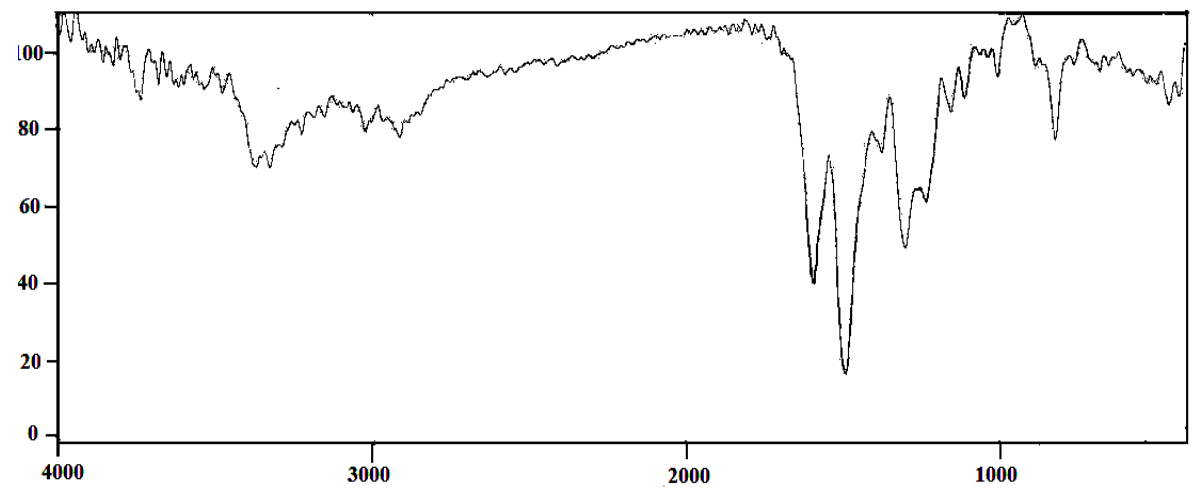

(a)

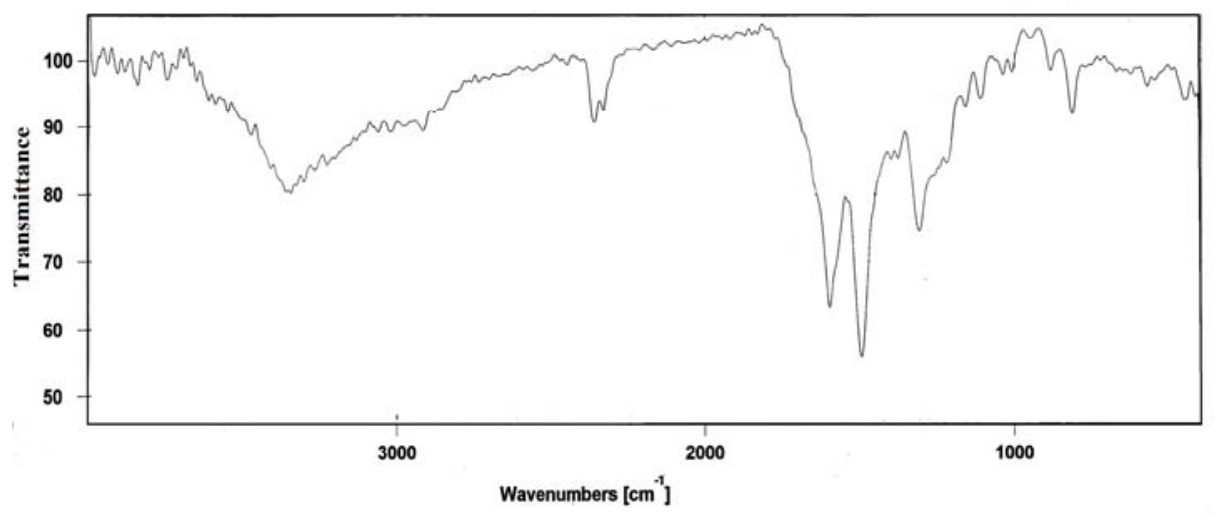

(b)

Fig. 1 FTIR absorption spectra of (a) Poly (aniline-co-o-toluidine) and (b) poly (pyrrole-coo-toluidine) copolymers.

\subsection{Immersion Test}

The results of immersion tests for uncoated, coated and coated scribed carbon steel specimens in both corrosive solutions are shown in (Table 1). The results of immersion test indicate that 
out of the two medium selected for corrosion studies, $0.1 \mathrm{M} \mathrm{HCl}$ is most corrosive in comparison of $5 \% \mathrm{NaCl}$ solution. The corrosion rate of uncoated steel in $0.1 \mathrm{M} \mathrm{HCl}$ is quite high. The poly (aniline-co-o-toluidine) copolymer coating was found to exhibit low permeability against water ingress. It showed PE of $78.41 \%$ in $0.1 \mathrm{M} \mathrm{HCl}$ solution and the PE in $5 \% \mathrm{NaCl}$ solution being $93.17 \%$. The effect of poly (pyrrole-co-o-toluidine) copolymer coating on steel is quite pronounced in both corrosive medium and it showed PE, $78.45 \%$ and $88.37 \%$ in $0.1 \mathrm{M} \mathrm{HCl}$ and $5 \% \mathrm{NaCl}$ solution, respectively. The presence of scribed mark on the copolymer coating only marginally affects its performance and the \% PE of scribed specimens was higher than the poly (o-toluidine) coating. This confirms the self passivating nature of the copolymer coating. The better performance of polyaniline coating is probably due to increased participation of polyaniline coating in the oxide formation. The \% PE of poly (pyrrole-co-o-toluidine) coated steel is significantly higher than homopolymer but lower than the poly (aniline-co-o-toluidine) copolymer coated steel samples. The corrosion performance of polyaniline homopolymer coating was found better than poly (o-toluidine) coating. The results obtained by immersion test are also supported by potentiodynamic polarization study.

Table 1: Results of immersion tests

\begin{tabular}{|c|c|c|c|c|}
\hline $\begin{array}{l}\text { Corrosive } \\
\text { Medium }\end{array}$ & Description of the sample & $\begin{array}{c}\text { Immersion } \\
\text { period (days) }\end{array}$ & $\begin{array}{l}\text { Corrosion } \\
\text { rate (mpy) }\end{array}$ & $\% \mathrm{PE}$ \\
\hline \multirow[t]{7}{*}{$0.1 \mathrm{M} \mathrm{HCl}$} & Uncoated steel & 30 & 19.081 & - \\
\hline & $\begin{array}{l}\text { Poly (aniline-co-o-toluidine) } \\
\text { coated }\end{array}$ & $"$ & 4.11 & 78.41 \\
\hline & $\begin{array}{l}\text { Poly (aniline-co-o-toluidine) } \\
\text { coated scribed }\end{array}$ & " & 5.02 & 73.67 \\
\hline & $\begin{array}{l}\text { Poly (pyrrole-co-o- } \\
\text { toluidine) coated steel }\end{array}$ & " & 4.11 & 78.45 \\
\hline & $\begin{array}{l}\text { Poly (pyrrole-co-o- } \\
\text { toluidine) coated scribed } \\
\text { steel }\end{array}$ & ", & 5.50 & 71.17 \\
\hline & Polyaniline coated & , & 3.41 & 82.12 \\
\hline & Poly(o-toluidine) coated & ", & 13.05 & 31.60 \\
\hline \multirow[t]{5}{*}{$5 \% \mathrm{NaCl}$ solution } & Uncoated steel & " & 6.02 & - \\
\hline & $\begin{array}{l}\text { Poly (aniline-co-o-toluidine) } \\
\text { coated }\end{array}$ & , & 0.40 & 93.17 \\
\hline & $\begin{array}{l}\text { Poly (aniline-co-o-toluidine) } \\
\text { coated scribed }\end{array}$ & " & 2.51 & 61.47 \\
\hline & $\begin{array}{l}\text { Poly (pyrrole-co-o- } \\
\text { toluidine) coated steel }\end{array}$ & , & 0.70 & 88.37 \\
\hline & $\begin{array}{l}\text { Poly (pyrrole-co-o- } \\
\text { toluidine) coated scribed }\end{array}$ & , & 2.51 & 58.27 \\
\hline
\end{tabular}


steel

Polyaniline coated

2.08

65.44

Poly(o-toluidine) coated

3.52

41.69

\subsection{Open Circuit Potential Measurements}

The OCP value $\left(E_{\text {ocp}}\right)$ of uncoated, polyaniline, poly (o-toluidine), poly (aniline-co-otoluidine) and poly (pyrrole-co-o-toluidine) copolymer (both scribed and unscribed) coated steel was monitored with time in both $0.1 \mathrm{M} \mathrm{HCl}$ and $5 \% \mathrm{NaCl}$ solution and the results are shown in (Figures 2-3). An analysis of the results of OCP measurements in corrosive solution show that when steel is covered with a single homopolymer or copolymer films, potentials are shifted towards more noble values compared with the uncoated steel indicating that these systems have a greater resistance to corrosion. In the case of the uncoated carbon steel the variations in potential corresponds to a system found in an active dissolution process. With increasing immersion period, there is a continuous increase in the negative potential till a steady potential is obtained. However, the final potential is still nobler than the potential of uncoated steel. The noble shift in potential is more pronounced for polyaniline and both copolymers coatings than poly (o-toluidine) coating. In case of coated scribed samples, after an initial increase in potential, a decrease in the potential is observed; this is followed by a constant potential. However, the final potential is again nobler than the potential of uncoated steel.

A noble potential for coated steel in comparison to bare steel indicates that polymer coated systems have a greater resistance to corrosion [24]. The protection offered by the polyaniline, poly (o-toluidine), poly (aniline-co-o-toluidine) and poly (pyrrole-co-o-toluidine) is attributed to both barrier effect and formation of passive oxide as a result of redox reaction at the steel and polymer interface [26]. The barrier effect is operative as long as coatings remains intact and isolate the substrate from corrosive environments. The initial OCP started to increase as a result of the initiation of corrosion process under the coating leading to anodic dissolution of steel. As the amount of water held within the pores of the coating increased, the mobility of corrosive species through the film increased. In this context, the porosity of the coating has much importance for initiation and progression of corrosion phenomenon under the coating. During this period, the barrier efficiency of the coating had diminished due to the increased amount of electrolyte held by the coating. The behaviour of polyaniline coating in all corrosive solutions is appreciable during the initial hours of immersion period; however, the copolymer coatings provided best protection during $200 \mathrm{hrs}$ of immersion. This is attributed to the better barrier behaviour of the copolymer coating than homopolymer coatings owing to the presence of a uniform and dense film of the copolymer on the steel substrate. The better performance of polyaniline coating than poly (o-toluidine) coating is probably due to more participation of polyaniline coating in the oxide formation. In case of coated scribed sample, though the initial OCP was higher than coated steel sample owing to the break in the coating, however, the coating immediately repassivated as a result of redox reaction and attained a potential close to the potential of coated steel and matched up to the end of immersion period 
of $200 \mathrm{hrs}$. The findings suggest that protection mechanism other than barrier protection is operating and is consistent with the reports of other authors [27, 28].

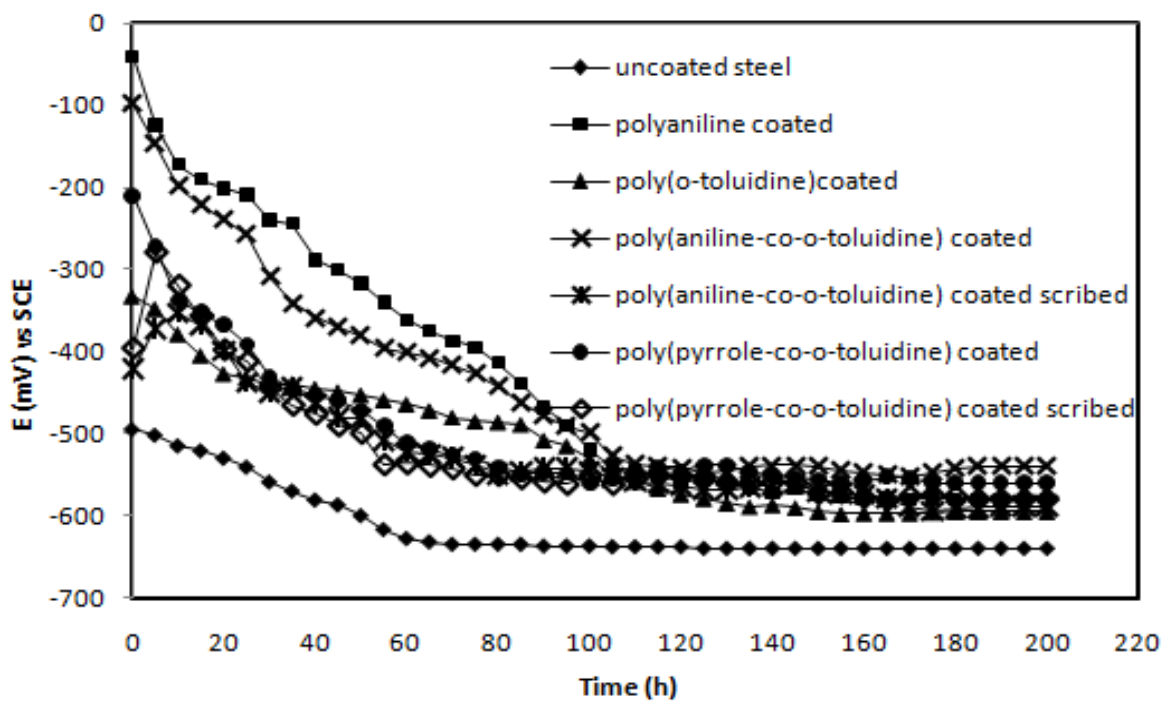

Fig. $2 E_{\text {corr }}$ Vs. time plot in $0.1 \mathrm{M} \mathrm{HCl}$ for $(\checkmark)$ uncoated steel; $(\boldsymbol{\square})$ polyaniline coated; $(\boldsymbol{\Delta})$ poly (o-toluidine) coated; $(\times)$ poly (aniline-co-o-toluidine) coated; $(*)$ poly (anilineco-o-toluidine) coated scribed; $(\bullet)$ poly (pyrrole-co-o-toluidine) coated and $(\diamond)$ poly (pyrrole-co-o-toluidine) coated scribed.

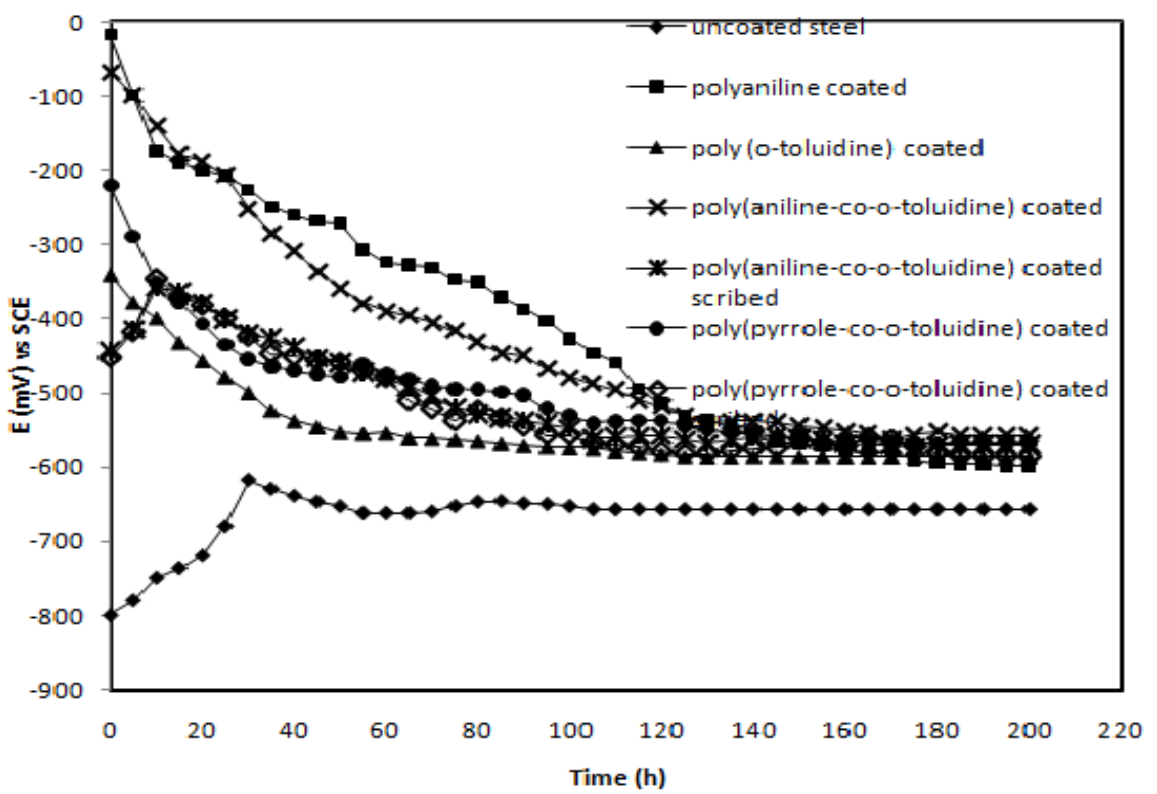

Fig. $3 E_{\text {corr }}$ vs. time plot in $5 \% \mathrm{NaCl}$ for $(\checkmark)$ uncoated steel; ( $\left.\boldsymbol{\square}\right)$ polyaniline coated; ( $\left.\boldsymbol{\Delta}\right)$ poly (o-toluidine) coated; $(\times)$ poly (aniline-co-o-toluidine) coated; $(*)$ poly (anilineco-o-toluidine) coated scribed; $(\bullet)$ poly (pyrrole-co-o-toluidine) coated and $(\diamond)$ poly (pyrrole-co-o-toluidine) coated scribed. 


\subsection{Potentiodynamic Polarization Measurements}

The potentiodynamic polarization curves for uncoated, poly (aniline-co-o-toluidine), poly (pyrrole-co-o-toluidine), polyaniline and poly (o-toluidine) coated steel recorded in $0.1 \mathrm{M}$ $\mathrm{HCl}$ and $5 \% \mathrm{NaCl}$ solution, respectively are shown in (Figures 4-7). The values of corrosion potential $\left(E_{\text {corr }}\right)$, corrosion current density $\left(I_{\text {corr }}\right)$, cathodic beta $\left(b_{\mathrm{c}}\right)$, anodic beta $\left(b_{\mathrm{a}}\right)$ and corrosion rate obtained from these curves are listed in (Table 2). In $0.1 \mathrm{M} \mathrm{HCl}$ the tafel extrapolations show that both poly (aniline-co-o-toluidine) and poly (pyrrole-co-o-toluidine) copolymer coatings on steel shifted the corrosion potential in nobler direction from $(-522 \mathrm{mV}$ to $-116 \mathrm{mV}$ and $-231 \mathrm{mV}$ vs $\mathrm{Ag} / \mathrm{AgCl}$ electrode) respectively. The positive shift in $E_{\text {corr }}$ confirms the best protection of the mild steel when its surface is covered by copolymer coatings. Also the corrosion current density $\left(I_{\text {corr }}\right)$ decreases which reduces the corrosion rate by an amount of several thousand times lower than the uncoated steel. The polyaniline coated sample also behaves in a similar manner and shows appreciable reduction in values of $E_{\text {corr }}$ and $I_{\text {corr. }}$. The results of potentiodynamic polarization curves for homopolymer and copolymers coated samples obtained in $5 \% \mathrm{NaCl}$ solution show almost identical trend as obtained for $0.1 \mathrm{M} \mathrm{HCl}$. There is a substantial positive shift in the corrosion potential and reduction in $I_{\text {corr }}$ of both copolymer and homopolymer coated steel relative to uncoated steel causing a substantial lowering in the corrosion rate. The values of electrochemical parameters favour the existence of a strong passivating coating having barrier effect on the surface of the mild steel coated with polymers. In case of homopolymer coating, the polyaniline coated samples provides better protection than poly (o-toluidine) coated samples in both mediums. This is attributed to the better participation of polyaniline coating in oxide formation. The potentiodynamic curves for copolymers coated scribed steel (fresh and after 1 month immersion) indicate that the damage inflicted on the coating do not adversely affect its performance. The corrosion rates of scribed samples are still lower than the corrosion rate of bare steel. This again supports the passivation property of the both copolymer coatings.

The potentiodynamic polarization curves for copolymers coated steel (both scribed and unscribed) and individual homopolymer coated steel samples were also recorded after 30 days of immersion in the respective corrosive medium. The results indicate that though there is some deterioration in the protective properties of the coating but the corrosion rate is still lower than the bare steel. This is indicative of high chemical stability of the polymer coatings. 


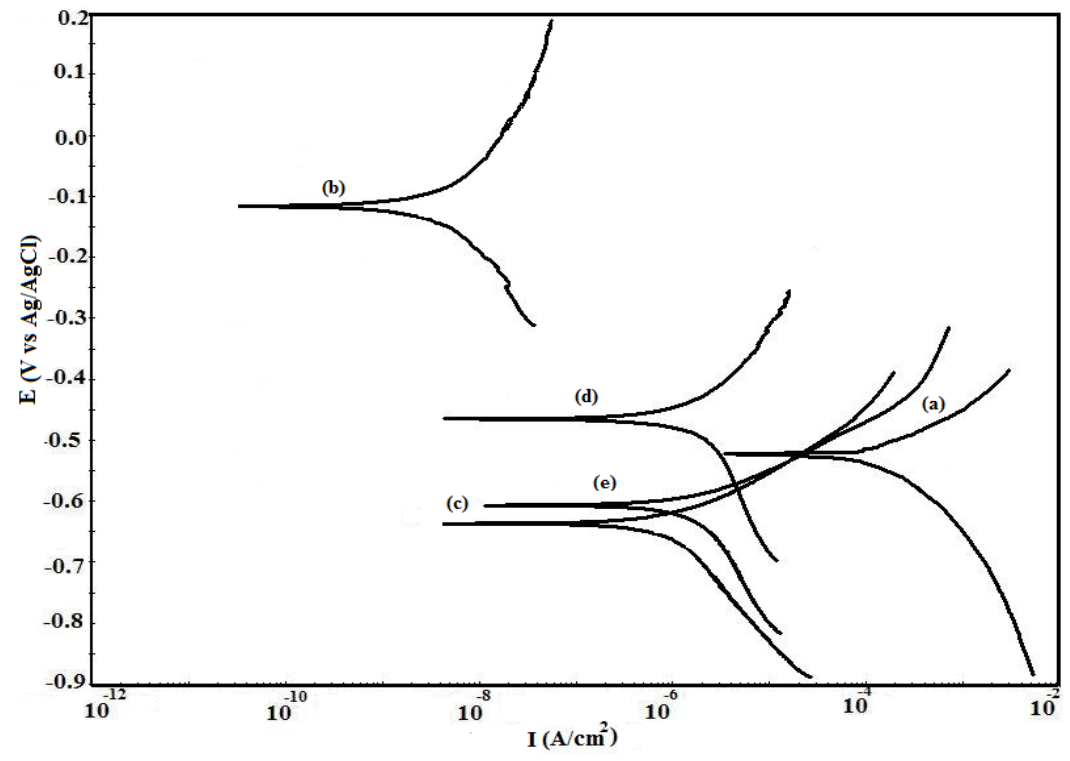

Fig. 4 Potentiodynamic polarization curves in $0.1 \mathrm{M} \mathrm{HCl}$ for (a) uncoated steel; (b) Poly (aniline-co-o-toluidine) coated (Fresh sample); (c) Poly (aniline-co-o-toluidine) coated (After 1 month immersion); (d) Poly (aniline-co-o-toluidine) coated scribed (Fresh sample) and (e) Poly (aniline-co-o-toluidine) coated scribed (After 1 month immersion).

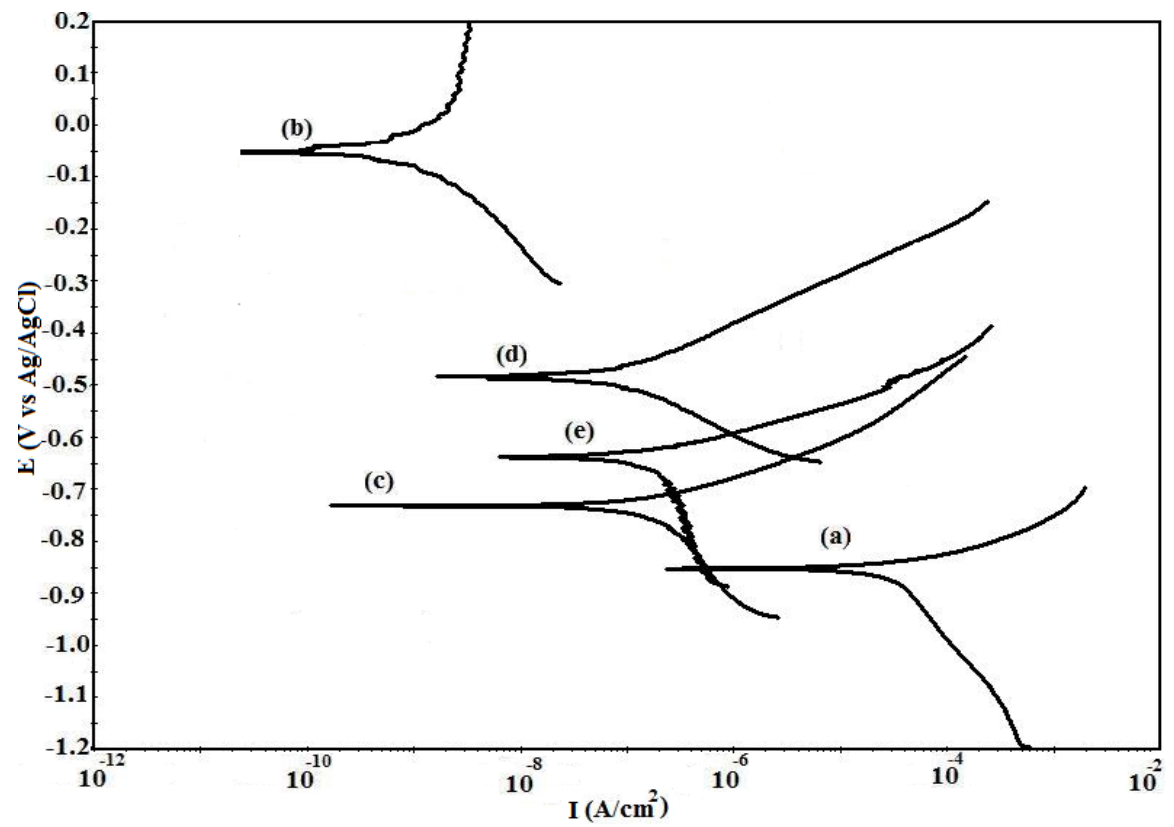

Fig. 5 Potentiodynamic polarization curves in $5 \% \mathrm{NaCl}$ for (a) uncoated steel; (b) Poly (aniline-co-o-toluidine) coated (Fresh sample); (c) Poly (aniline-co-o-toluidine) coated (After 1 month immersion); (d) Poly (aniline-co-o-toluidine) coated scribed (Fresh sample) and (e) Poly (aniline-co-o-toluidine) coated scribed (After 1 month immersion). 


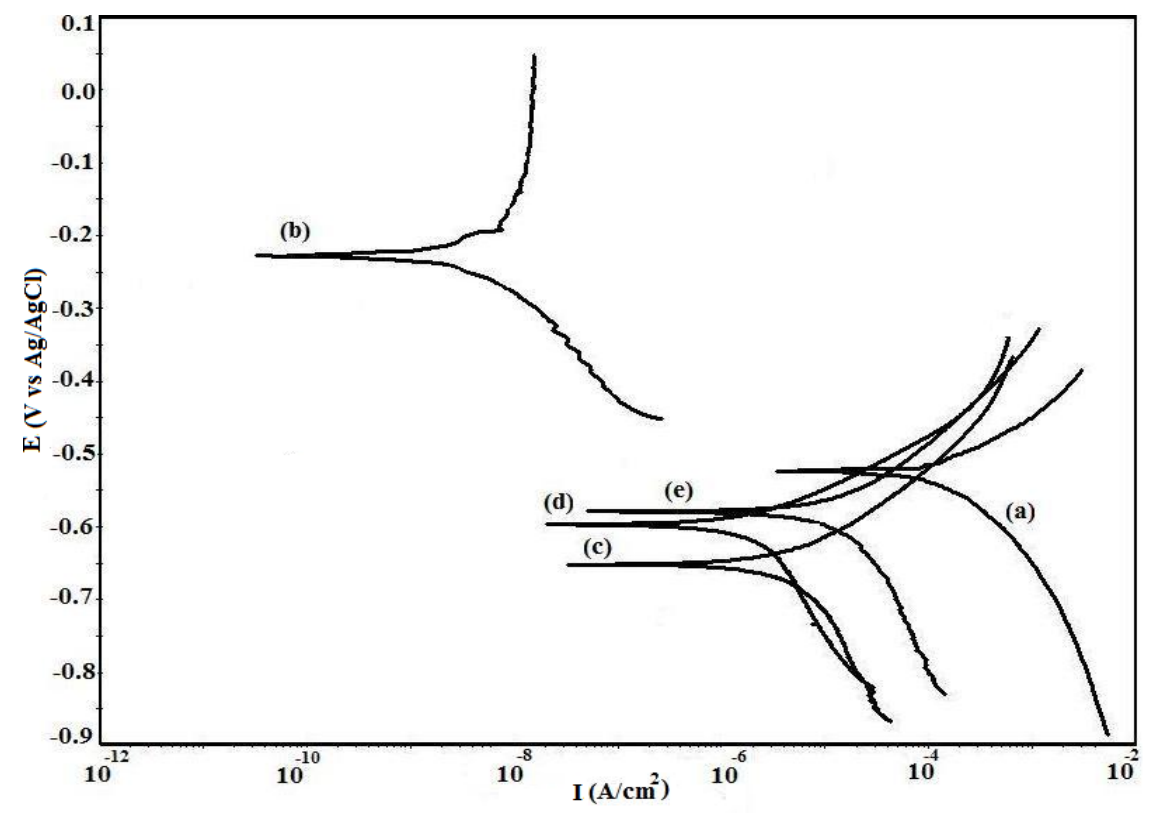

Fig. 6 Potentiodynamic polarization curves in $0.1 \mathrm{M} \mathrm{HCl}$ for (a) uncoated steel; (b) poly (pyrrole-co-o-toluidine) coated (Fresh sample); (c) poly (pyrrole-co-o-toluidine) coated (After 1 month immersion); (d) poly (pyrrole-co-o-toluidine) coated scribed (Fresh sample) and (e) poly (pyrrole-co-o-toluidine) coated scribed (After 1 month immersion).

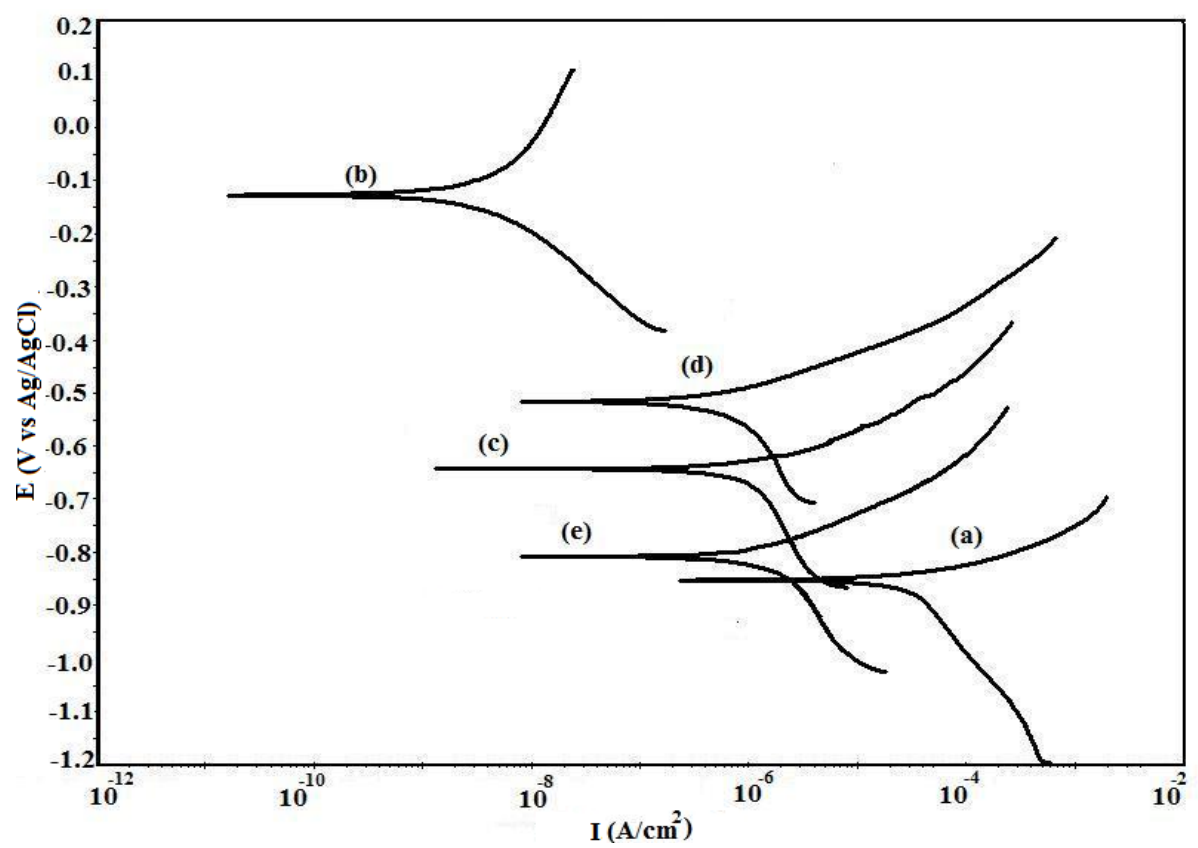

Fig. 7 Potentiodynamic polarization curves in $5 \% \mathrm{NaCl}$ for (a) uncoated steel; (b) poly (pyrrole-co-o-toluidine) coated (Fresh sample); (c) poly (pyrrole-co-o-toluidine) coated (After 1 month immersion); (d) poly (pyrrole-co-o-toluidine) coated scribed (Fresh sample) and (e) poly (pyrrole-co-o-toluidine) coated scribed (After 1 month immersion). 
Table 2: Results of potentiodynamic polarization measurements

\begin{tabular}{|c|c|c|c|c|c|c|}
\hline $\begin{array}{l}\text { Corrosive } \\
\text { Medium }\end{array}$ & Description of the sample & $\begin{array}{c}I_{\text {corr }} \\
\left(\mu \mathrm{A} / \mathrm{cm}^{2}\right)\end{array}$ & $\begin{array}{l}E_{\text {corr }} \\
(\mathrm{mV})\end{array}$ & $\begin{array}{l}\text { Cathodic beta } \\
(\mathrm{mV})\end{array}$ & $\begin{array}{l}\text { Anodic beta } \\
(\mathrm{mV})\end{array}$ & $\begin{array}{l}\text { Corrosion } \\
\text { rate (mpy) }\end{array}$ \\
\hline \multirow[t]{13}{*}{$0.1 \mathrm{M} \mathrm{HCl}$} & Uncoated steel & 1994.110 & -522 & 279.435 & 138.311 & 150.412 \\
\hline & Poly (aniline-co-o-toluidine) coated (Fresh sample) & 0.063 & -116 & 366.650 & 324.352 & 0.004 \\
\hline & $\begin{array}{l}\text { Poly (aniline-co-o-toluidine) coated (After } 1 \text { month } \\
\text { immersion) }\end{array}$ & 9.073 & -636 & 243.782 & 107.756 & 0.068 \\
\hline & $\begin{array}{l}\text { Poly (aniline-co-o-toluidine) coated scribed (Fresh } \\
\text { sample) }\end{array}$ & 8.838 & -465 & 4793.001 & 718.272 & 6.665 \\
\hline & $\begin{array}{l}\text { Poly (aniline-co-o-toluidine) coated scribed (After } \\
1 \text { month immersion) }\end{array}$ & 27.251 & -606 & 1034.761 & 119.681 & 8.055 \\
\hline & Poly (pyrrole-co-o-toluidine) coated (Fresh sample) & 0.091 & -231 & 221.232 & 4058.851 & 0.006 \\
\hline & $\begin{array}{l}\text { Poly (pyrrole-co-o-toluidine) coated (After } 1 \text { month } \\
\text { immersion) }\end{array}$ & 67.551 & -651 & 498.848 & 148.003 & 5.093 \\
\hline & $\begin{array}{l}\text { Poly (pyrrole-co-o-toluidine) coated scribed (Fresh } \\
\text { sample) }\end{array}$ & 31.852 & -596 & 548.590 & 118.948 & 2.402 \\
\hline & $\begin{array}{l}\text { Poly (pyrrole-co-o-toluidine) coated scribed (After } \\
1 \text { month immersion) }\end{array}$ & 156.055 & -579 & 373.726 & 145.405 & 11.762 \\
\hline & Polyaniline coated (Fresh sample) & 0.068 & -145 & 219.165 & 545.594 & 0.008 \\
\hline & Polyaniline coated (After 1 month immersion) & 0.011 & -404 & 366.650 & 324.352 & 0.005 \\
\hline & Poly (o-toluidine) coated (Fresh sample) & 0.021 & -444 & 306.924 & 540.484 & 9.35 \\
\hline & $\begin{array}{l}\text { Poly (o-toluidine) coated (After } 1 \text { month } \\
\text { immersion) }\end{array}$ & 19.181 & -557 & 5285.189 & 580.903 & 14.46 \\
\hline \multirow{13}{*}{$\begin{array}{l}5 \% \mathrm{NaCl} \\
\text { solution }\end{array}$} & Uncoated steel & 265.112 & -851 & 319.240 & 82.472 & 19.951 \\
\hline & Poly (aniline-co-o-toluidine) coated (Fresh sample) & 0.024 & -52 & 330.191 & 286.733 & 0.002 \\
\hline & $\begin{array}{l}\text { Poly (aniline-co-o-toluidine) coated (After } 1 \text { month } \\
\text { immersion) }\end{array}$ & 2.136 & -731 & 466.338 & 102.234 & 0.161 \\
\hline & $\begin{array}{l}\text { Poly (aniline-co-o-toluidine) coated scribed (Fresh } \\
\text { sample) }\end{array}$ & 0.514 & -484 & 99.819 & 95.046 & 0.038 \\
\hline & $\begin{array}{l}\text { Poly (aniline-co-o-toluidine) coated scribed (After } \\
1 \text { month immersion) }\end{array}$ & 2.349 & -637 & 134.235 & 81.934 & 0.177 \\
\hline & Poly (pyrrole-co-o-toluidine) coated (Fresh sample) & 0.040 & -129 & 199.071 & 413.889 & 0.003 \\
\hline & $\begin{array}{l}\text { Poly (pyrrole-co-o-toluidine) coated (After } 1 \text { month } \\
\text { immersion) }\end{array}$ & 18.693 & -643 & 107.671 & 131.121 & 1.410 \\
\hline & $\begin{array}{l}\text { Poly (pyrrole-co-o-toluidine) coated scribed (Fresh } \\
\text { sample) }\end{array}$ & 8.012 & -514 & 718.118 & 106.006 & 0.604 \\
\hline & $\begin{array}{l}\text { Poly (pyrrole-co-o-toluidine) coated scribed (After } \\
1 \text { month immersion) }\end{array}$ & 20.431 & -807 & 528.012 & 140.401 & 1.540 \\
\hline & Polyaniline coated (Fresh sample) & 0.090 & -82 & 195.062 & 474.735 & 0.007 \\
\hline & Polyaniline coated (After 1 month immersion) & 4.016 & -816 & 1525.198 & 3680.231 & 0.362 \\
\hline & Poly (o-toluidine) coated (Fresh sample) & 3.001 & -577 & 514.492 & 108.709 & 0.223 \\
\hline & $\begin{array}{l}\text { Poly (o-toluidine) coated (After } 1 \text { month } \\
\text { immersion) }\end{array}$ & 4.678 & -688 & 413.141 & 161.856 & 0.352 \\
\hline
\end{tabular}

\subsection{Atmospheric Test}

The samples taken after the completion of the atmospheric test were physically examined. The potentiodynamic polarization curves for uncoated, coated and coated scribed steel 
samples recorded in distilled water after 30 days exposure to open atmosphere are shown in (Figures 8 and 9$)$. The values of corrosion potential $\left(E_{\text {corr }}\right)$, corrosion current density $\left(I_{\text {corr }}\right)$, cathodic beta $\left(b_{c}\right)$, anodic beta $\left(b_{\mathrm{a}}\right)$ and corrosion rate obtained from these curves are listed in Table 3. Poly (aniline-co-o-toluidine) coating did not show any colour change and corrosion product on the surface of the substrate. In case of poly (pyrrole-co-o-toluidine) copolymer, the coating was found to be detached from the substrate at some places. Polyaniline coating shows comparatively poor adhesion and gets detached from the surface during the atmospheric exposure but perform better than the poly (o-toluidine) coating. In case of poly (o-toluidine) coating, it shows maximum deterioration and poor corrosion resistance. The tafel extrapolations show that in presence of copolymers and polyaniline coating the mild steel show a noble shift in corrosion potential and corrosion current density with respect to bare steel for the same condition. As a result of decrease in corrosion current density, the corrosion rate is still lower than the bare steel. It is clearly shown that the poly (aniline-co-otoluidine) coating could provide a much efficient barrier protection for longer periods with respect to the other copolymer and homopolymer coatings for atmospheric corrosion of mild steel. The copolymer coated scribed sample performed in a similar manner as unscribed even after one month of atmospheric exposure. After one month of atmospheric exposure, though the adherence of the copolymer coating was affected but it still maintained the protective properties giving excellent protection to the underneath metal.

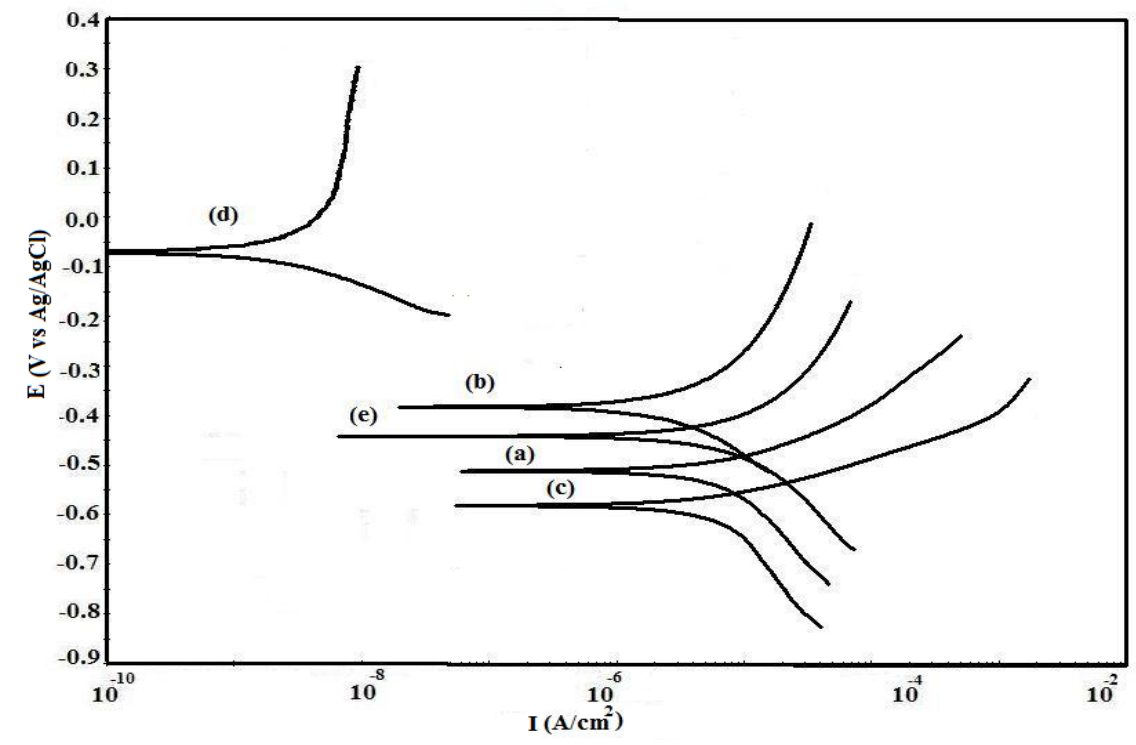

Fig. 8 Potentiodynamic polarization curves in distilled water $(\mathrm{pH} 6.5)$ for (a) uncoated steel; (b) Polyaniline coated; (c) Poly (o-toluidine) coated; (d) Poly (aniline-co-o-toluidine) coated and (e) Poly (aniline-co-o-toluidine) coated scribed steel after 30 days exposure to open atmosphere. 


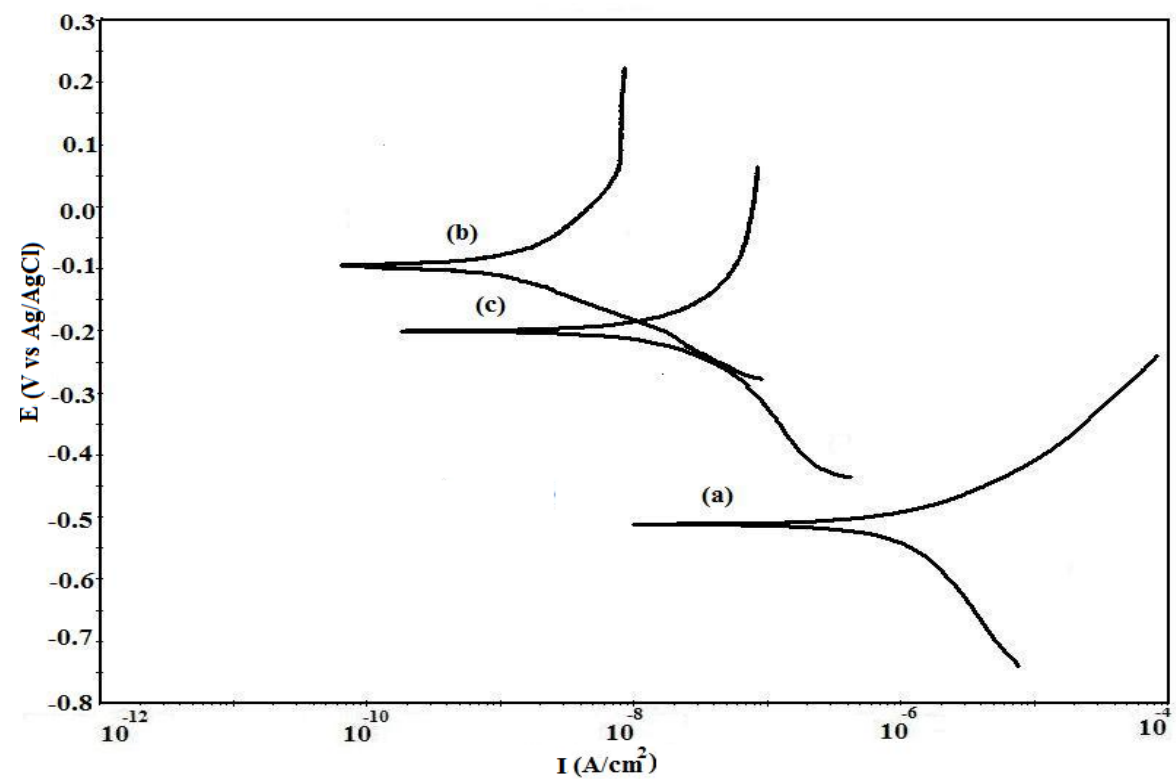

Fig. 9 Potentiodynamic polarization curves in distilled water ( $\mathrm{pH}$ 6.5) for (a) uncoated steel; (b) poly (pyrrole-co-o-toluidine) coated steel and (c) poly (pyrrole-co-o-toluidine) coated scribed steel after 30 days exposure to open atmosphere.

Table 3: Results of potentiodynamic polarization measurements after 1 month exposure to open atmosphere

\begin{tabular}{|c|c|c|c|c|c|}
\hline Description of the sample & $\begin{array}{c}I_{\text {corr }} \\
\left(\mu \mathrm{A} / \mathrm{cm}^{2}\right)\end{array}$ & $E_{\text {corr }}(\mathrm{mV})$ & $\begin{array}{l}\text { Cathodic beta } \\
\qquad(\mathrm{mV})\end{array}$ & $\begin{array}{l}\text { Anodic beta } \\
(\mathrm{mV})\end{array}$ & $\begin{array}{l}\text { Corrosion } \\
\text { rate(mpy) }\end{array}$ \\
\hline Uncoated steel & 15.271 & -511 & 642.265 & 169.347 & 1.152 \\
\hline $\begin{array}{l}\text { Poly (aniline-co-o-toluidine) } \\
\text { coated }\end{array}$ & 5.337 & -74 & 135.603 & 1551.400 & 0.004 \\
\hline $\begin{array}{l}\text { Poly (aniline-co-o-toluidine) } \\
\text { coated scribed }\end{array}$ & 15.881 & -441 & 504.540 & 556.322 & 1.051 \\
\hline $\begin{array}{l}\text { Poly (pyrrole-co-o-toluidine) } \\
\text { coated }\end{array}$ & 0.022 & -106 & 132.493 & 761.600 & 0.008 \\
\hline $\begin{array}{l}\text { Poly (pyrrole-co-o-toluidine) } \\
\text { coated scribed }\end{array}$ & 0.935 & -200 & 526.823 & 797.482 & 0.076 \\
\hline Polyaniline coated & 14.262 & -382 & 571.937 & 880.731 & 1.075 \\
\hline Poly(o-toluidine) coated & 10.711 & -581 & 580.607 & 104.727 & 0.980 \\
\hline
\end{tabular}




\subsection{Scanning Electron Microscopy}

The SEM micrograph of uncoated mild steel and polyaniline coated mild steel specimens is shown in Figure 10 (a) and (b). The SEM micrograph of poly (aniline-co-o-toluidine) copolymer coated specimen in Figure 10 (c), revealed that the formation of a closely packed, continuous and uniform layer. Figure 10 (d) showed the poly (pyrrole-co-o-toluidine) copolymer coated specimen and it was found dense and slightly less uniform in comparison of poly (aniline-co-o-toluidine) copolymer coating. The dense and continuous structure is consistent with the ability of the coating to protect the metal from corrosion. After immersion both coatings showed partial and localized removal of coating material.

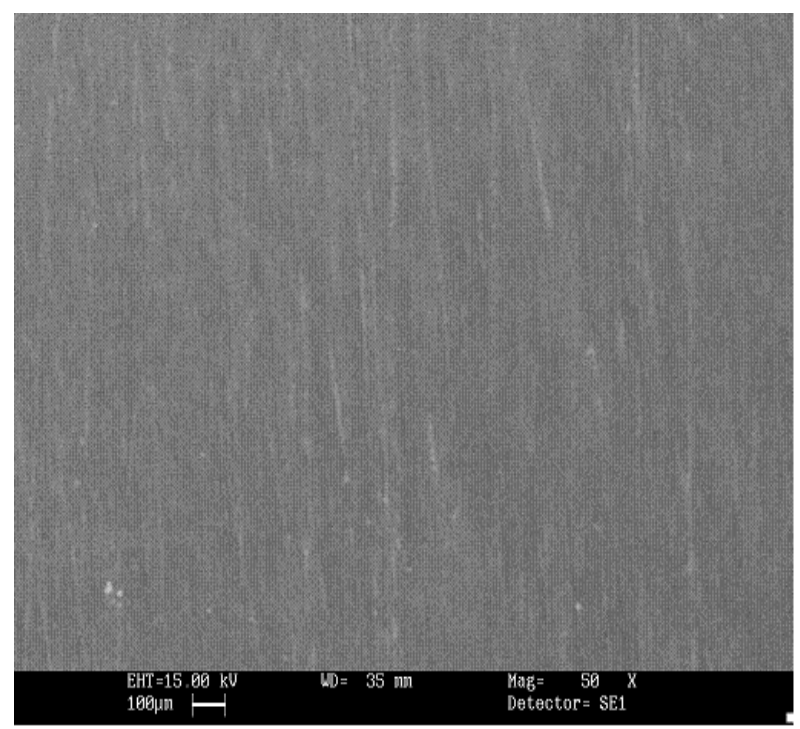

(a)

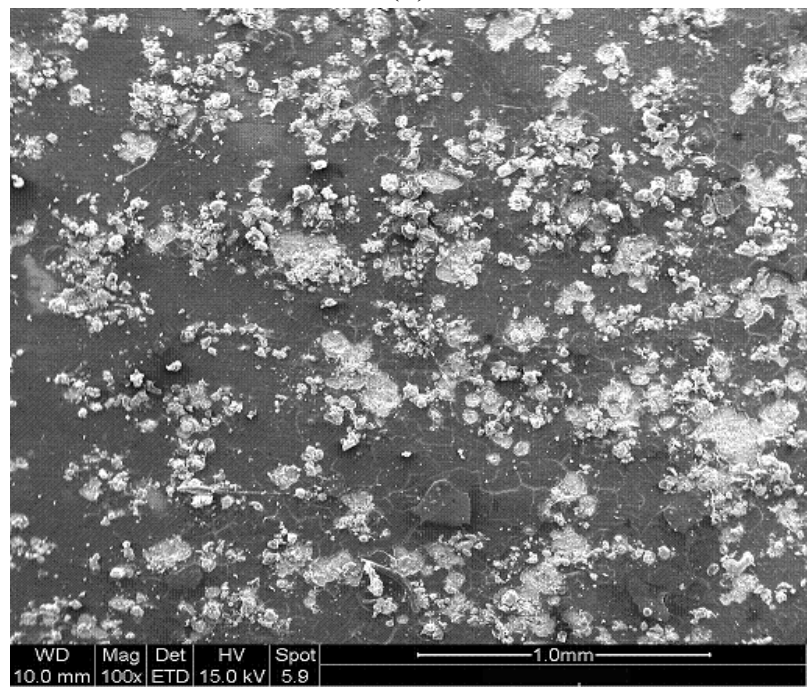

(b) 


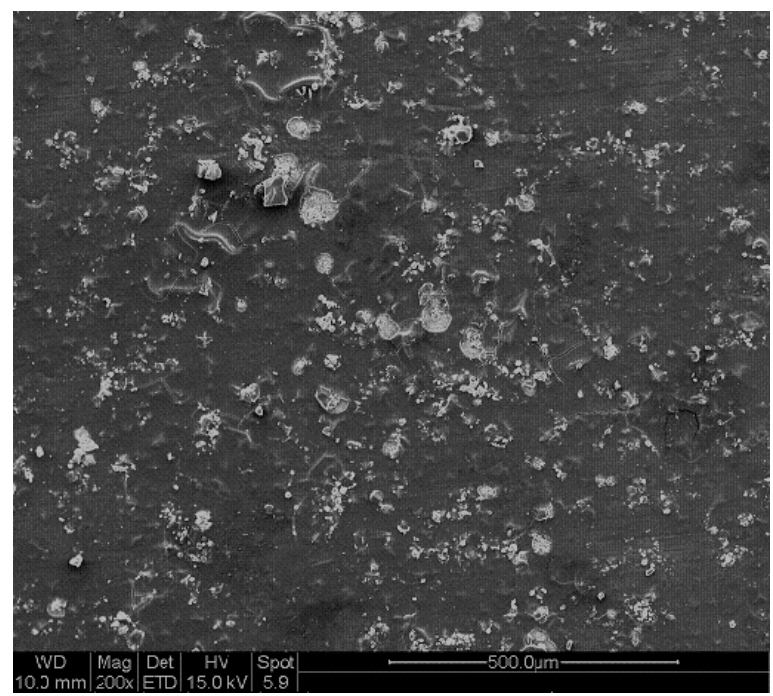

(c)

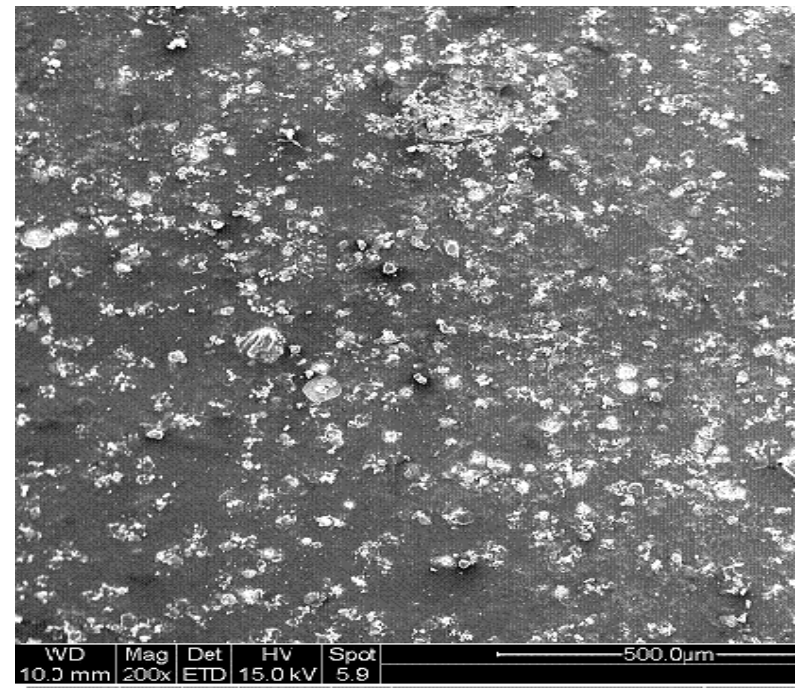

(d)

Fig. 10 SEM micrographs of (a) uncoated mild steel; (b) polyaniline coated; (c) poly (anilineco-o-toluidine) copolymer coated; and (d) poly (pyrrole-co-o-toluidine) copolymer coated specimen.

\section{CONCLUSIONS}

Poly (aniline-co-o-toluidine) and poly (pyrrole-co-o-toluidine) copolymers were synthesized by chemical oxidative copolymerization. The adherent and dark coloured coatings of copolymers were successfully casted on carbon steel by solution evaporation. The thickness of both copolymer coatings has been arranged to approximately same in order to compare their corrosion protection. The coatings of copolymers were more dense and uniform than homopolymer coatings. The results of immersion tests indicate that the corrosion rate for the 
copolymer coated steel is significantly lower than the homopolymer coatings in both corrosive medium under investigation. The result of OCP measurements show nobler potential for copolymer and homopolymer coated steel compared to the uncoated steel. Also the electrochemical measurements realized for corrosion behaviour of this coating on steel indicated to low permeability and stability in severe corrosive conditions. The presence of scribed mark on the coating does not significantly affect the integrity of the coating. Poly (aniline-co-o-toluidine) copolymer coating performed better than poly (aniline-co-otoluidine) and homopolymer coatings.

\section{ACKNOWLEDGEMENT}

The authors thankfully acknowledge the University Grants Commission, New Delhi, for financial assistance.

\section{REFERENCES}

[1] N. Ahmad, and A.G. MacDiarmid, Synth. Met., issue 2, 78 (1996) 103.

[2] B. Wessling, and J. Posdorfer, Electrochim. Acta., 45 (1999) 2139.

[3] J.R. Santos, Jr., L.H. Mattoso, and A.J. Motheo, Electrochim. Acta., (3-4) (1998) 309.

[4] V.T. Truong, P.K. Lai, B.T. Moore, R.F. Muscat, and M.S. Russo, Synth. Met., 110 (2000) 7.

[5] R.C. Patil, and S. Radhakrishnan, Prog. Org. Coat., 57 (2006) 332.

[6] S. Sathiyanarayan, S. Muthukrishnan, and G. Venkatachari, Prog. Org. Coat., 55 (2006) 5.

[7] F. Jiang, X.W. Guo, and Y.H. Wei, Synth. Met.,139 (2003) 335.

[8] P. Ocon, A.B. Cristobal, P. Herrasti, and E. Fatas, Corros Sci., 3 (2005) 649.

[9] M. G. Hosseini, M. Sabouri, and T. Shahrabi, Prog. Org. Coat., 60 (2007) 178.

[10] N. Ahmad, A.U. Malik, and M. Mobin, J. Ind. Chem. Soc., 84 (2007) 1.

[11] P. Pawar, A.B. Gaikwad, and P.P. Patil, Sci \& Tech of Adv. Mat., 7 (2006) 732.

[12] Y. Chem. X.H. Wang, J. Li, J. Lu, and F.S. Wang, Corros. Sci., 49 (2007) 3052.

[13] J. Fang, K. Xu, L. Zhu, Z. Zhou, and H. Tang, Corros. Sci., 49 (2007) 4232.

[14] M.R. Huang, X.G. Li, Y.L. Yang, X.S. Wang, and D. Yan, J. Appl. Polym. Sci.,81 (2001) 1838.

[15] Y. Wei, W.W. Focke, G.E. Wnek, A. Ray, and A.G. MacDiarmid, J. Phys. Chem., 93 (1989) 495.

[16] Y. Wei, R. Hariharan, and S.A. Patel, Macromolecules., 23 (1990) 764.

[17] G. Bereket, E. Hur, and Y. Sahin, Prog. Org. Coat., 54 (2006) 63.

[18] S. Yalcinkaya, T. Tuken, B. Yazici, and M. Erbil, Current. Appl. Phys., 10 (2010) 783.

[19] D. Kumar, Synth Met., 114 (2000) 369.

[20] C. T. Kuo, S. Z. Weng, and R.L. Huang, Synth. Met., 88 (1997) 101.

[21] Y. Z. Wang, J. Joo, C. H. Hsu, J. P. Pouget, A.J. Epstein, Macromolecules., 27 (1994) 5871.

[22] M. Leclerc, J. Guay, L.H. Dao, Macromolecules., 22 (1989) 649.

[23] X.G. Li, L.X. Wang, Y. Jin, Z. L. Zhu, Y.L. Yang, J. of Appld. Polym. Sci., 82 (2001) 510 . 
[24] R. Vera, R. Schrebler, P. Cury, R. Del Rio, H. Romero, J. Appl. Electrochem., 37 (2007) 519.

[25] R. Ansari, A.H. Alikhani, J. Coat. Technol. Res., 6 (2) (2009) 221.

[26] T. Schauer, A. Joos, L. Dulog, C.D. Eisenbach, Prog. Org. Coat., 33 (1998) 20.

[27] W.K. Lu, R.L. Elsenbaumer, B. Wessling, Synth. Met., 71 (1995) 2163.

[28] A.A. Pud, G.S. Shapoval, P. Kamarchik, N.A. Ogurtsov, V.F. Gromovaya, I.E. Mayronyuk and Y.V. Kontsur, Synth. Met., 107 (1999) 111. 